\title{
ANÁLISE DO PRODUTO "RISCO SACADO" COMO ALTERNATIVA DE FINANCIAMENTO PARA FORNECEDORES
}

Josiane Martins Groeff ${ }^{1}$

Andréia Arnold ${ }^{1}$

Dusan Schreiber ${ }^{1}$

${ }^{1}$ Associação Pró-Ensino Superior em Novo (ASPEUR) 


\section{ANÁLISE DO PRODUTO "RISCO SACADO" COMO ALTERNATIVA DE FINANCIAMENTO PARA FORNECEDORES}

\section{Resumo}

O presente trabalho teve como objetivo, analisar o produto Risco sacado como alternativa de financiamento, desenvolvido pela empresa Delta e adotado pela empresa denominada ABC para ofertar crédito a seus fornecedores. Esta organização é definida como líder no setor de calçados, bolsas e acessórios femininos através de sua plataforma de marca, atualmente localiza-se na região do Vale dos Sinos, RS. Para atender o objetivo do estudo, foi realizada uma pesquisa exploratória e descritiva, o método utilizado foi o estudo de caso com abordagem qualitativa e quantitativa, a coleta de dados se deu por meio de observação não participante e distribuição de questionários á fornecedores com volume de faturamento superior. Os resultados obtidos demonstram satisfação por parte dos fornecedores que contrataram o produto, pois segundo estes, o Risco Sacado é seguro, de fácil acesso, e oferece custos reduzidos quando comparados a outros financiamentos disponíveis.

Palavras-chave: fornecedores, financiamento, Risco Sacado.

\section{Introdução}

Gerir as finanças de maneira correta é de extrema importância para as pessoas tanto físicas quanto jurídicas. Para manter a qualidade de vida e honrar com as dívidas, o gasto familiar deve ser menor que valor dos rendimentos mensais. As empresas convivem com o mesmo cenário, o custo total não pode ser superior à receita, e para dar continuidade a suas atividades, a organizações devem dispor de capital de giro para conseguir financiar o seu ciclo operacional. (ASSAF NETO, 2011)

Quando uma empresa encontra-se em recesso financeiro, precisa buscar recursos de terceiros para suprir suas necessidades. O setor contábil analisa, descreve e registra os dados financeiros das organizações, é com base nestas informações que gestor tem visão geral sobre as receitas, custos e lucros de seu negócio, o que facilita as decisões assertivas. Ao definir melhorias ou modificações no sistema, o administrador deve considerar invariavelmente os benefícios, riscos e impactos gerados por suas ações. (HERLING E MORITZ, 2010)

Segundo dados da Associação Nacional de Fomento Comercial (ANFAC, 2015), nos últimos anos a busca por créditos em bancos, instituições financeiras e cooperativas teve um aumento considerável. Este fato demonstra que cresceu o número de organizações com dificuldades na gestão de seus ativos. Quando a empresa trabalha com recursos escassos, o capital de giro reduz e influencia diretamente o ciclo operacional. SILVA (2001)

O objetivo deste trabalho foi analisar o produto Risco sacado, adotado como alternativa de financiamento por uma organização industrial de grande porte do setor de calçados, denominada neste artigo como ABC. A pesquisa justifica-se pelo aumento da demanda de financiamentos, e pela importância da contratação de um empréstimo que
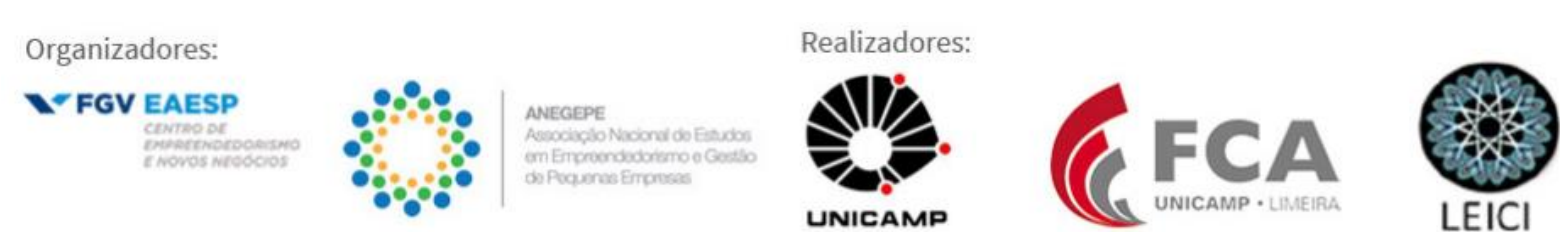
satisfaça as necessidades da organização e ao mesmo tempo ofereça boas condições de pagamento. $\mathrm{O}$ delineamento metodológico consiste em um estudo de caso único, sendo que a pesquisa pode ser classificada como aplicada, exploratória e descritiva, com abordagem qualitativa e quantitativa.

O trabalho está dividido em sete capítulos. No primeiro encontra-se a introdução, o segundo e o terceiro capítulo abordam respectivamente os conceitos da administração de fornecedores e administração financeira com auxílio de financiamentos, já o capítulo descreve o Produto Risco sacado como opção de financiamento. A metodologia está descrita no capítulo cinco, a empresa em estudo ABC é apresentada no capítulo seis, onde também encontra-se os resultados do estudo, e por fim, o capítulo sete trata das considerações finais.

\section{Administração de fornecedores}

Conforme Christopher (2011), a Cadeia de Suprimentos é formada por elementos que incluem todas as empresas e organizações que interagem, direta ou indiretamente, por meio de fornecedores ou clientes, desde a origem do produto ou serviço até o consumidor final. A Gestão da Cadeia de Suprimentos é um conjunto de abordagens utilizadas com o intuito de integrar de forma eficiente fornecedores, fabricantes e distribuidores (armazéns, depósitos e centro de distribuição), de modo que o produto ou serviço seja produzido e distribuído na quantidade, localização e tempo certos. Para Heinritz e Farrell (1983), o principal objetivo da cadeia de suprimentos é atingir a qualidade desejada pelo cliente com custos reduzidos para as organizações.

Para que a Gestão da Cadeia de Suprimentos seja efetuada de forma adequada, é necessário o conhecimento da configuração geral do negócio. De acordo com Lambert (1998 apud SIMON; PIRES, 2013, p. 57) a cadeia possui três aspectos estruturais primários, a saber: (i) membros: Para tornar a cadeia gerenciável, é recomendado separar os membros entre primários e de apoio. Membros primários são todas as empresas que produzem um determinado produto para o mercado ou cliente final, já membros de apoio são empresas que fornecem conhecimento, recursos e ativos para a cadeia de suprimento, como exemplo é citado os bancos que disponibilizam recursos financeiros, proprietários que alugam seus imóveis para empresas entre outros; (ii)Dimensões estruturais: para gerenciar a cadeia de suprimentos é necessário analisar três dimensões como: estrutura horizontal, que corresponde ao número de camadas de clientes e fornecedores da cadeia de suprimento, os clientes e fornecedores diretos da empresa correspondem a primeira camada, esta estrutura pode ser curta com poucas camadas ou longa; estrutura vertical é o número de clientes e fornecedores dentro de cada uma das camadas, pode ser estreita com poucas camadas, ou larga com muitas camadas de fornecedores e clientes em cada uma delas; posição horizontal da empresa foco, é a posição em que o fornecedor ou cliente se encontra dentro da cadeia de suprimentos;(iii)Tipos de ligações de processos: existem vários níveis de ligação de processo, é de extrema importância alocar os recursos escassos entre as diferentes ligações, principalmente nas mais críticas. Entre os membros de uma cadeia de suprimento são encontrados quatro tipos de ligações de processos, tais como, ligações gerenciadas, onde a empresa principal integra um ou mais processos entre fornecedores e clientes; ligações monitoradas, em que há o acompanhamento e gerenciamento das ligações de processos
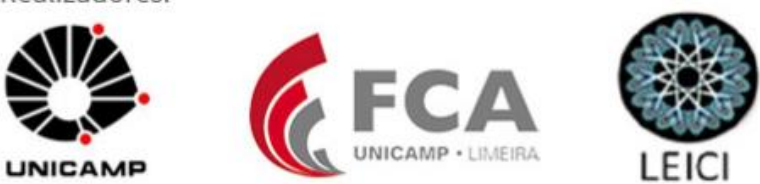
sempre que necessário; ligações não gerenciadas, referem-se à ligação onde a empresa foco não está envolvida de forma ativa e não são críticas o bastante para serem monitoradas; ligações de não membros são os não membros da cadeia de suprimentos, porém membros da empresa em questão. Dentre os processos de negócio-chave da cadeia de suprimentos, podemos destacar os mais recentes como o Gerenciamento do Relacionamento com o Fornecedor, em que um depende do outro para girar, as empresas de fornecedores confiáveis e os fornecedores de oportunidade. Essa integração envolve um nível entre as partes da cooperação, comprometimento mútuo, visão em longo prazo, incluindo, ainda, ferramentas como a parceria para gerenciar conflitos e estruturar as relações.

De acordo com Moura (2009, p. 61), "a parceria requer frequentemente compromisso de significativo tempo gerencial e também de outros recursos, o objetivo é adequar o tipo de parceria com a situação da empresa e o ambiente organizacional". Outro processo, atualmente em alta, é a tendência para a terceirização, em que não apenas materiais e componentes são terceirizados, como também serviços que geralmente eram realizados internamente. Tal motivação e ampliação destacam-se pela oportunidade de produzir ou comprar produtos/materiais a preços significativamente mais baixos que os de mercado. Segundo Christopher (2011, p. 13), a terceirização "estende a cadeia de valor para além das fronteiras da empresa", ou seja, a cadeia de suprimento torna-se a cadeia de valor. O valor (custo) não apenas criado pela empresa local em uma rede, mas por todas as entidades que se conectem umas as outras. Essa "empresa estendida", como alguns chamam, torna-se o veículo pelo qual a vantagem competitiva é conquistada, ou perdida.

A terceirização é um processo que requer estratégias bem definidas e objetivos claros. Serra (2006) define esses objetivos como: (i) redução de custos: é quando o valor exercido no mercado é menor que o praticado internamente pela empresa. A contratação de profissionais especializados em um determinado processo agrega qualidade ao produto a um preço reduzido, devido ao domínio das técnicas da produtividade; (ii) foco em atividades estratégicas ou de maior retorno: é a definição do ponto de vista estratégico ou de retorno financeiro maior das atividades que são prioridade para a empresa. Dessa forma, o restante é repassado a terceiros, deixando a empresa enxuta, flexível e com o processo de informações claro e objetivo sobre o negócio; (iii) melhor qualidade: é a utilização de empresas, matériasprimas e pessoas qualificadas a fim de garantir qualidade nos produtos desenvolvidos ou serviços prestados; (iv) acesso a novas tecnologias: tem relação com a busca por fornecedores capacitados; (v) mudanças organizacionais: as empresas precisam estar atentas e aptas para mudar suas estratégias devido a alterações constantes decorrentes de oscilações do mercado; (vi) racionalização produtiva: após a delimitação das atividades da empresa, deve-se racionalizar o sistema produtivo, repassando a terceiros as funções extras; (vii) especialização flexível: as empresas tonam-se flexíveis, gerenciando e desenvolvendo um conjunto de células produtivas e eficazes, o que envolve fornecedores de bens e de serviços; (viii) adequação às tendências internacionais: a concorrência mundial demanda que as empresas se adequem à realidade internacional, envolvendo o uso de fornecedores de outros países.

Serra (2006) destaca que uma indústria pode ser contratante e contratada em um mesmo período, pode atuar sob a condição de subcontratada como terceirizada ou primária, secundária, terciária entre outras, esta classificação se dá segundo a localização da ordem ou nível da fase de manufatura dos produtos, ou serviços subcontratados. O autor cita algumas
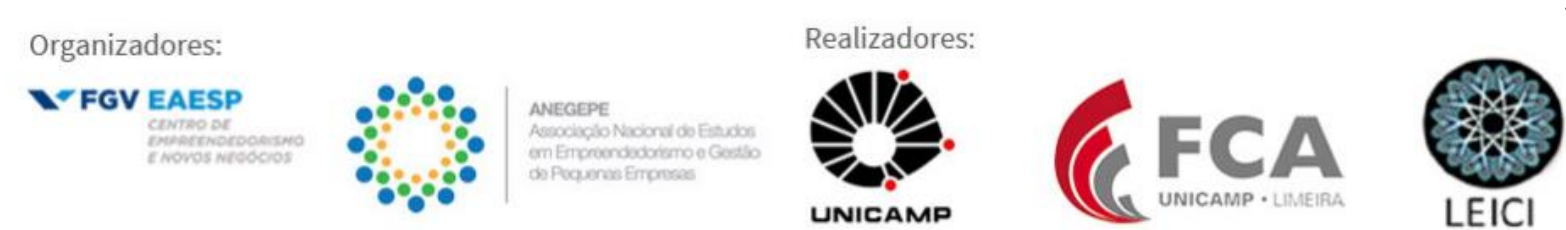
vantagens decorrentes da subcontratação e terceirização, como o aumento de qualidade do serviço, transferência de tecnologias sem acréscimo nos custos, diminuição e controle de custos fixos, variáveis e estoques da empresa contratante, redução de riscos de obsolescência de equipamentos, possibilidade de crescimento com investimentos baixos, ampliação de mercado para pequenas e médias empresas, entre outros. Como desvantagens, o mesmo destaca as dificuldades de encontrar parceiros ideais, assim como em formular e controlar contratos com as parcerias, problemas com o corpo funcional da companhia, desconhecimento da legislação trabalhista, dificuldades no contato com a alta administração, em controlar os custos internos com a parceria, e no relacionamento com sindicatos, risco de desemprego e não absorção da mão de obra na mesma proporção, falta de cuidados na escolha dos fornecedores, possibilidade de a empresa não repassar ao consumidor a economia de escala obtida, entre outros.

\section{Administração com auxílio de financiamentos}

De acordo com Assaf Neto (2011), os recursos correntes da empresa, cuja conversão em caixa é possível em um período curto, é denominado capital de giro. Conforme Brigham e Houston (1999), a origem da nomenclatura capital de giro dá-se através dos ianques, pois eles utilizavam carroças que carregavam suas mercadorias e percorriam seus destinos vendendo seus produtos. O mascate, proprietário da carroça, vendia os produtos ou girava para adquirir lucros, por isso capital de giro.

Viana (2013) destaca que toda organização, independentemente do seu porte ou segmento, necessita de capital de giro para atender suas necessidades e dar continuidade às atividades. No entanto, se este capital for administrado incorretamente, a empresa sofrerá consequências negativas. Assaf Neto (2011) acrescenta que o capital de giro representa os recursos necessários para financiar o ciclo operacional de uma empresa, ou seja, as necessidades financeiras da organização para honrar com suas responsabilidades, este período abrange desde o momento da aquisição de matérias-primas ou mercadorias, até o recolhimento da receita obtida com a comercialização do produto acabado.

De acordo com Viana (2008) o Ciclo Financeiro é representado pelo número de dias que os recursos ficam parados entre a saída de caixa, proveniente de pagamentos relacionados á fornecedores de matéria-prima, até o momento da entrada de caixa que corresponde aos recebimentos de vendas de produtos realizados a clientes. O autor destaca que o ciclo financeiro é o resultado das políticas de estocagem e de financiamento da empresa, sendo também influenciado pelas condições estruturais do setor no qual atua e pelo ambiente econômico do momento.

Para Gitman (2004) é possível estimar a saída de caixa, mas as entradas são complexas e pouco assertivas, e quanto maior for a previsão de entradas em caixa, menor será a necessidade de capital de giro para a organização. Segundo o autor, as decisões financeiras de uma empresa, incluindo as de Capital de Giro, são baseadas em comparações entre o risco e o retorno, para ele a verificação da aceitação do produto e a identificação de possíveis erros operacionais, maximizando os prováveis retornos financeiros à empresa. Silva (2001) complementa afirmando que as dificuldades financeiras localizadas em uma empresa, podem ser motivadas pela redução das vendas ou pelo gerenciamento inadequado dos recursos
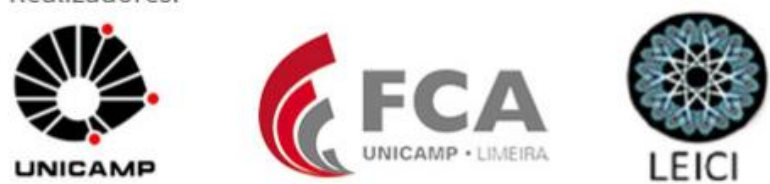
financeiros. Tais dificuldades causam a diminuição das receitas, o que afeta as atividades operacionais da empresa e consequentemente o poder de liquidez.

Conforme Assaf Neto e Silva (2002, p.22), a falha na sincronização de informações entre as três atividades principais de uma empresa (produção, venda e cobrança) pode provocar indefinição e riscos na ligação entre os estoques e duplicatas a receber. Esse descompasso entre os fluxos de pagamentos e recebimentos deverá ser afiançado pelo capital circulante líquido, que também é conhecido por capital de giro líquido. "Quanto maior for o Capital Circulante Líquido mantido por uma organização, mais ampla é a folga financeira e menor é o risco de insolvência", pois esta relação financeira é estreita. Os autores comentam ainda que o conflito do risco-retorno na administração do capital de giro se dá quando a empresa investe valores de capital em diversos ativos, gerando a incerteza do retorno. Para eles, quando os negócios de uma empresa estão em constante crescimento, os recursos podem ser desviados para ativos não circulantes, o que faz com que o Capital Circulante Líquido CCL - se torne negativo. Por outro lado, um CCL alto prejudica a rentabilidade da empresa, já que o excesso de ativo circulante pode indicar ineficiência do uso dos recursos financeiros disponíveis, todos os demais ativos circulantes, exceto os estoques, ficam expostos aos efeitos da inflação, isto resulta em desgaste do poder aquisitivo dos valores a receber. Sendo assim os autores concluem que o objetivo da administração do capital de giro é gerenciar os ativos e passivos circulantes, de forma a manter um nível adequado do capital circulante líquido.

Conforme Herling e Moritz (2010), os gestores financeiros são responsáveis pelas decisões referentes a investimentos, financiamentos e operações. Segundo Camargo (2014), a decisão de financiamento consiste essencialmente na captação de recursos por parte da empresa para aquisição de matéria prima, folha de pagamento, investimento em ativos imobilizados, capital de giro, impostos e outros gastos relativos à sua atividade. $\mathrm{O}$ autor acrescenta que o capital de uma organização pode ser composto tanto de recursos próprios de acionistas quanto de terceiros, que consistem em instituições financeiras e fornecedores.

Segundo dados da Associação Nacional de Fomento Comercial (ANFAC, 2015), a busca por financiamentos em bancos, instituições financeiras e cooperativas, teve um acréscimo de 8,5\% em julho/2015 em relação ao mês anterior. Em julho de 2014, o aumento registrado foi de $7,0 \%$, já no acumulado do ano a procura do consumidor por crédito cresceu $5,1 \%$ no primeiro semestre de 2015, comparado com o mesmo período do ano de 2014.

Conforme Oliveira (2002, p. 24 apud Agustini, 1996), quando ocorre um desequilíbrio financeiro, as empresas tem possibilidade de contratar um dos inúmeros tipos de financiamentos disponíveis no mercado, tais como as aplicações financeiras, empréstimos, abertura de contas correntes e/ou poupança, seguro e ordem de pagamento". De acordo com Camargo (2014), cada fonte de financiamento gera um custo diferenciado, cabe aos gestores das organizações, à análise e escolha de um produto acessível e com baixo impacto financeiro.

Como opções de financiamento, Oliveira (2002) comenta sobre: (i) Alienação Fiduciária, onde bens como máquinas, veículos, terrenos, imóveis e produtos em estoque, servem como garantia através de contrato público ou particular; (ii) Fiança, cuja garantia pessoal decorre de contrato que induz o fiador a pagar o débito do afiançado, caso este não o faça; (iii) Hipoteca, nesta fonte a garantia é constituída de bens móveis, tais como casas, terrenos, salas comerciais, apartamentos entre outros; (iv)Aval, neste tipo o avalista se

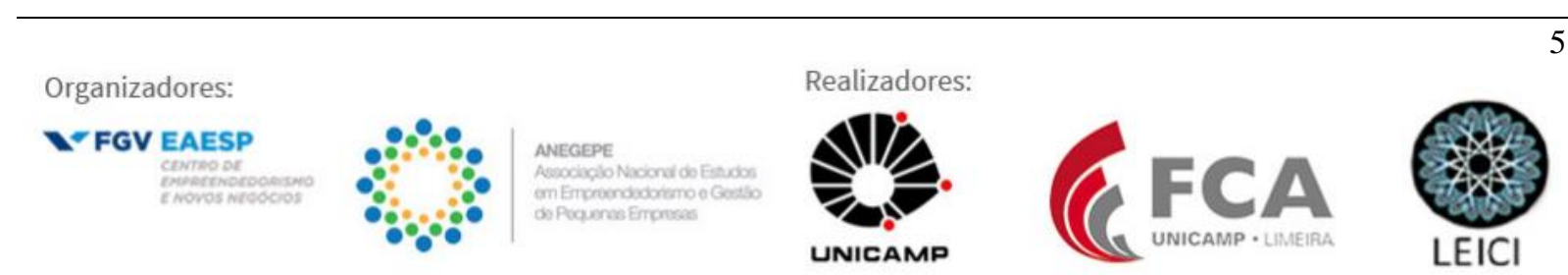


compromete a pagar a dívida caso o devedor principal não cumpra com o contrato, se da através de letra de câmbio, duplicatas, conhecimento de transporte, conhecimento de depósito e nota promissória;(v) Penhor ou Caução, onde bens móveis como máquinas e equipamentos, estoque de matérias-primas ou produtos acabados, e também duplicatas por meio de contrato por instrumento público ou particular são penhorados e/ ou caucionados. O autor acrescenta que as empresas costumam quitar seus créditos junto a bancos ou fornecedores, pois a inadimplência não é bem vista pela ética empresarial.

Conforme Mellagri Filho e Ishikawa (2000), o sistema financeiro ou bancário, é o nome dado ao conjunto de instituições e operações ocupadas com o fluxo de recursos monetários entre os agentes econômicos. Basicamente, versa sobre mercado de emprestadores e tomadores de recursos financeiros, tendo os juros como principal remuneração por essa atividade. Sobre o assunto, Machado (2015) destaca quatro segmentos encontrados no mercado financeiro brasileiro, a saber: (i) Mercado Monetário: neste são realizadas as operações em curto prazo, os papéis de maior negociação são emitidos pelo Banco Central, que é submisso à política monetária do Governo Federal, tem como finalidade o financiamento do déficit público; (ii) Mercado de Crédito: segmento que observa a necessidade de crédito a curto, médio e longo prazo, são negociáveis principalmente o financiamento de bens duráveis, investimentos e capital de giro das empresas;(iii) Mercado de Capitais: atende basicamente as necessidades de crédito a médio e longo prazo, em especial investimentos em ativos imobilizados, essas operações são efetivadas entre investidores e emissores (devedores), e contratadas em bolsa de valores ou no "balcão", através de emissão privada com debêntures e ações;(iv) Mercado Cambial: é responsável pela venda de moedas e instrumentos de fomento estrangeiro.

Cavalcante (2005 p. 23) descreve os componentes do Sistema Financeiro Nacional (SFN) como "um conjunto de instituições financeiras, sejam elas públicas ou privadas, constituído por dois subsistemas, sendo o normativo e o operário". De acordo com o autor o subsistema normativo é responsável por regular e controlar o subsistema operativo, esta atribuição se dá com base em normas legais expedidas pela autoridade monetária, ou pela oferta seletiva de crédito levada a efeito pelos agentes financeiros do governo. O subsistema operativo é constituído por instituições financeiras, públicas ou privadas que atuam no mercado financeiro.

Sobre o CMN (Conselho Monetário Nacional), Cavalcante (2005) afirma ser o órgão mais importante do SFN, cujo principal objetivo é a formulação da política da moeda e do crédito, objetivando o incentivo do desenvolvimento econômico no Brasil. Este órgão é responsável também por determinar as diretrizes gerais dos mercados monetários, de crédito e cambiais, além de ser o regulamentador e fiscalizador das instituições financeiras. Segundo o autor, o CMN é constituído pelo Ministro da Fazenda como presidente, Ministro do Planejamento e pelo Presidente do Banco Central (Bacen).

De acordo com Ferreira (2014), o Banco Central (Bacen) é um órgão executivo vinculado ao Ministério da Fazenda, que exerce e faz-se exercer as disposições que lhe são impostas pela legislação e normas vindas do Conselho Monetário Nacional - CMN em vigor. $\mathrm{O}$ autor destaca que o principal objetivo do Bacen, é garantir o poder aquisitivo da moeda brasileira por meio da preservação da liquidez da economia, assim como o ajuste dos níveis de reservas internacionais, o desenvolvimento de poupança e o constante aperfeiçoamento do

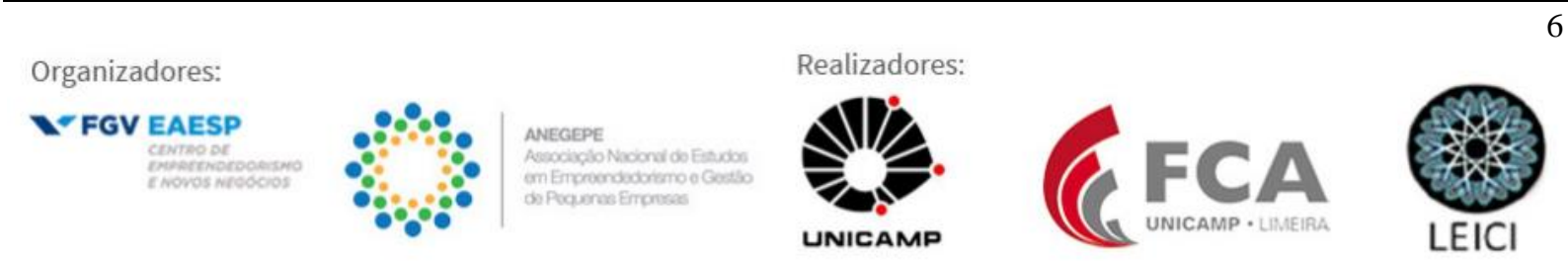


Sistema Financeiro Nacional. O autor ainda descreve as principais atribuições do Bacen como: (i) emitir papel-moeda e moeda metálica dentro dos padrões de liquidez da economia firmados pelo CMN; (ii) executar os serviços do meio circulante; (iii) receber recolhimentos compulsórios e voluntários das instituições financeiras e bancárias, também para controle de liquidez; (iv) realizar operações de redesconto e empréstimos as instituições financeiras;(v) regular a execução dos serviços de compensação de cheques e outros papéis;(vi) efetuar operações de compra e venda de títulos públicos federais; (vii) exercer o controle de crédito; (viii)exercer a fiscalização das instituições financeiras, assegurando a confiabilidade dos processos de intermediação; (ix) autorizar o funcionamento das instituições financeiras; (x)definir as condições para o exercício de quaisquer cargo de direção nas instituições financeiras, resguardando a qualidade e a idoneidade da gestão das atividades de intermediação financeira; (xi) vigiar a interferência de outras empresas nos mercados financeiros e de capitais; (xii)controlar o fluxo de capitais estrangeiros no país.

Com embasamento no portal BCB (2016), compreende-se outras atribuições ligadas ao Banco Central do Brasil, que estão relacionadas à definição da taxa Selic, por meio do Comitê de Política Monetária (Copom), o qual foi fundado em junho de 1996 com o objetivo de estabelecer as diretrizes da política monetária e definir as taxas de juros.

Conforme Cavalcante (2005), a Comissão de Valores Mobiliários - CVM é uma entidade autárquica, criada em 1976, vinculada ao Ministério da Fazenda, suas responsabilidades incidem em desenvolver, controlar e fiscalizar o mercado de valores mobiliários no Brasil. O autor descreve as atribuições da CVM como sendo: (i)Assegurar o funcionamento eficiente e regular dos mercados de bolsas e de balcão; (ii)Regulamentar, orientar e fiscalizar os fundos de investimento; (iii)Proteger os titulares de valores mobiliários, contra emissões irregulares e atos ilegais de administradores e acionistas controladores de companhias, ou de administradores de carreira de valores mobiliários; (iv)Evitar ou coibir modalidades de fraude ou manipulação destinadas a criar condições artificiais de demanda, oferta ou preço de valores mobiliários negociados no mercado; (v)Assegurar o acesso do público a informações sobre valores mobiliários negociados e as companhias que os tenham emitido; (vi)Assegurar a observância de práticas comerciais equitativas no mercado de valores mobiliários; (vii)Estimular a formação de poupança e sua aplicação em valores mobiliários; (viii)Promover a expansão e o funcionamento eficiente e regular do mercado de ações, e estimular as aplicações permanentes em ações do capital social das companhias abertas. Para Ferreira (2014, p. 30) “(...), é importante frisar que a atuação da CVM diz respeito tão somente ao mercado de valores mobiliários, que são títulos de propriedade ou de crédito, emitidos tanto pelo governo quanto pelos entes privados, visando obter recursos".

Segundo Assaf Neto (2012), o último grupo ligado ao subsistema normativo do Sistema Nacional Financeiro é composto pelo Banco do Brasil (BB), o Banco Nacional de Desenvolvimento Econômico e Social (BNDES) e Caixa Econômica Federal (CEF). Conforme o autor, o Banco do Brasil (BB) é uma sociedade anônima de capital misto, que tem como controlador a União, assumindo três funções principais ao desenvolver suas atividades: (i)Agente financeiro do Governo Federal: receber os tributos e as rendas federais, ser o administrador pagador e recebedor de numerários no exterior e realizar os pagamentos constantes no orçamento da União; (ii) Banco Comercial: disputar mercado com outras
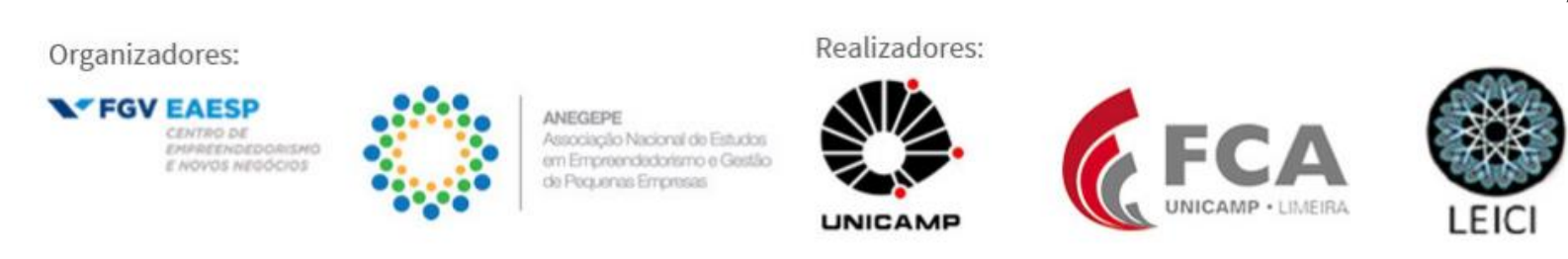
instituições do mesmo gênero, manter contas correntes de pessoas físicas e jurídicas, bem como conta poupança, conceder crédito, dentre outras atividades típicas de bancos comerciais; (iii) Banco de Investimento e Desenvolvimento: executor principal das políticas de crédito rural, comercial, industrial e de serviços, além de promover o crescimento, fortalecendo o setor empresarial através de apoio a setores estratégicos e às pequenas e médias empresas.

Cavalcante (2005) caracteriza o Banco Nacional de Desenvolvimento Econômico e Social - BNDES - como uma empresa pública, cujo principal papel, é o de executar as políticas de investimentos do Governo Federal junto a empresas a ele filiadas, apoiando investimentos estratégicos necessários ao desenvolvimento do país. Como empresa filiada, o autor cita a Agência Especial de Financiamento Industrial (FINAME), que tem como finalidade principal financiar a compra ou venda de equipamentos industriais e agrícolas, e a BNDES Participações S.A. (BNDESPAR), que destina a capitalização de empresas nacionais.

Vidor (2014) descreve a Caixa Econômica Federal - CEF - como órgão que executa atividades características a de bancos comercias como o Banco do Brasil. Tem como principal característica a autonomia, e apresenta um objetivo claramente social. De acordo com o autor, a CEF é o principal agente do Sistema Financeiro de Habitação focado no financiamento da casa própria, principalmente no segmento de baixa renda, possui exclusividade na administração das loterias federais, é considerado principal arrecadador do FGTS, possui também o monopólio nas operações de penhor.

Cavalcante (2005) comenta que os componentes do Subsistema Operativo são os setores do Sistema Financeiro Nacional, sejam eles bancários e não bancários, que efetivam as intermediações financeiras, e viabilizam o financiamento e as transações bancárias, buscando obter remuneração conhecida como spread, que é a diferença entre a taxa de juros recebida e a taxa de juros paga aos poupadores. Para o autor o funcionamento do SFN é agrupado em funções creditícias ou patrimoniais, sendo que para crédito em curto prazo têm-se os Bancos comerciais e Múltiplos, caixas Econômicas, Cooperativas de crédito e Factoring. Para crédito de médio a longo prazo citam-se Bancos de Investimentos, Desenvolvimento e Leasing, já para a concessão de crédito ao consumidor, aponta-se as Financeiras, Caixas Econômicas, Sociedade de Crédito ao Microempreendedor e Leasing. Para crédito habitacional, o autor cita a Caixa Econômica Federal, a Sociedade de Créditos Mobiliários e os Bancos Múltiplos, em busca de Intermediação de Títulos e Valores Mobiliários comenta-se sobre a Bolsa de Valores, Bolsa de Mercadorias e Futuros, Sociedades Corretoras e Distribuidoras e Agentes Autônomos de Investimentos. O autor ainda comenta sobre a busca por Seguro, Previdência complementar e Capitalização que é realizada por Seguradoras, Fundações de Seguridade Social, Companhias de Capitalização, e Instituições Financeiras, já o Arredondamento Mercantil que pode ser realizado por companhias de Leasing.

Conforme analise de Vieira (2008), há diversas fontes disponíveis para a captação de recursos, o administrador deve definir as estratégias para o financiamento, identificar a modalidade correta e optar por aquela que melhor atenderá as necessidades de organização.

\section{Produto Risco sacado como opção de financiamento}

Risco Sacado é um programa de antecipação de recebíveis criado por uma instituição financeira denominada neste trabalho como Delta. Confiabilidade, velocidade no

Organizadores:

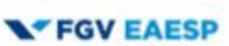

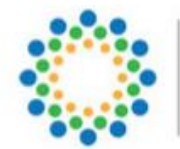
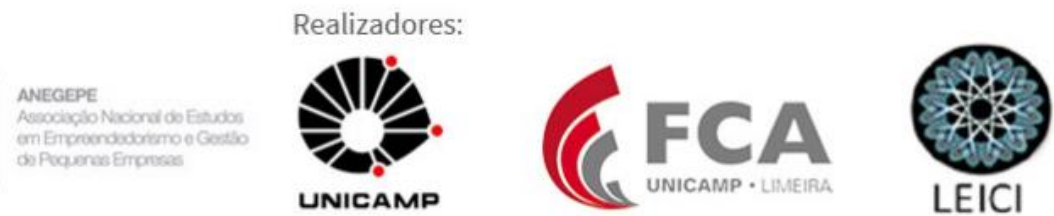
processamento, eliminação de controle manual e redução de custo com operações financeiras de desconto de títulos, foram algumas das vantagens observadas pelas organizações que utilizam este serviço. De acordo com Jankovski (2007, p. 13 apud BLATT, 2007), no desconto de título o cliente leva seus recebíveis ao banco, endossa-os, transferindo-os à instituição financeira, que antecipa esse valor, com determinado deságio, e efetua a cobrança dos recebíveis nos seus respectivos vencimentos. Caso não haja quitação dos mesmos, o banco cobra regressivamente de seu cliente, com os encargos correspondentes.

O produto em questão é uma ferramenta automatizada, o acesso ao serviço se dá mediante cadastro prévio solicitado pela empresa contratante, neste momento o cliente recebe uma senha para fazer login na página do produto Risco sacado e assim obter maiores informações, de acordo com a Delta, essas etapas são fundamentais para manter a segurança e integridade das informações durante os acessos. As empresas que contratam o serviço da organização Delta consolidam parceria através de contrato, segundo Moura (2009, p. 61 apud LAMBERT, 2008) "a parceria é uma relação comercial personalizada com base na confiança mútua, no relacionamento aberto, onde são compartilham os riscos e as recompensas,". Esta associação alcança resultados dificilmente conquistados com atuação individual, e proporciona aos clientes a possibilidade de antecipar os seus recebíveis com um custo reduzido.

Sobre o contrato assinado entre banco e empresa, é possível destacar alguns pontos que representam risco para o cliente, tais como: (i)Após a contratação da cessão de crédito por parte dos fornecedores/ cedentes, há possibilidade de regresso, seja pelo cliente ou o próprio contratante; (ii) o cliente tem responsabilidade de pagar ao banco os valores dos créditos cedidos até mesmo na hipótese de devolução de mercadorias, não prestação do serviço ou ocorrência de múltiplas cessões do mesmo crédito pelo cedente, para diferentes cessionários ou qualquer outro fato que possa comprometer o valor integral dos créditos cedidos;(iii) $\mathrm{O}$ cliente deve acertar ou reclamar qualquer pendência diretamente com o cedente, isentando o banco de qualquer responsabilidade frente ao cedente diante da ocorrência destes eventos; (iv) quanto ao pagamento das cessões realizadas pelos cedentes nas respectivas datas de vencimento, fica autorizado, pelo cliente, o débito em a sua conta corrente dos valores necessários para a liquidação dos créditos cedidos decorrentes desse convênio; cabe também ao cliente manter tais saldos disponíveis diariamente em conta, do contrário taxas e juros poderão ser acrescidos aos valores.

Formalizado os termos contratuais entre banco e empresa, é realizado o cadastro dos fornecedores, após a ratificação a empresa contratante envia informações por meio de arquivos eletrônicos, sobre os títulos disponíveis para antecipação de seus fornecedores, títulos estes que serão recolhidos em quarenta e cinco dias após a data de emissão das Notas Fiscais. Machado $(2010$, p.17) comenta que "o contas a receber $(C / R)$ representa os créditos da empresa junto a seus clientes", para o autor a liquidação do $C / R$ é a principal fonte de recursos de caixa de grande parte das empresas, assim o default destas contas, implica na falta de recursos para pagamento das obrigações da própria empresa com seus fornecedores.

A facilidade de acesso a informações sobre o produto Risco sacado, auxilia os fornecedores na seleção dos títulos de acordo com sua necessidade diária ou semanal, na definição da conta para receber o crédito e na conclusão da operação. Ao contratar este produto, é aplicado uma Taxa de Deságio correspondente ao CDI + 1,25\% a.a., somente sobre

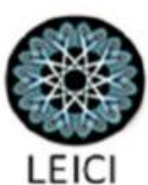


o período da aquisição, ou seja, entre a data da operação e o vencimento efetivo do título em questão. Lunardi (2009, p. 26) conceitua a taxa CDI como "Certificado de Depósito Interbancário, título de emissão das instituições financeiras que lastreia as operações do mercado interbancário possibilitando a transferência de recursos das instituições superavitárias, garantindo liquidez ao mercado", segundo o autor a taxa DI é apurada de CETIP.

Dentre as vantagens da contratação do produto desenvolvido pela empresa Delta perante produtos do mesmo segmento, observa-se a rapidez e automatização na contratação, também uma flexibilidade em exigências feitas por outras instituições financeiras referentes a limites de outras operações, ou vínculo contratual com a empresa em questão. A aquisição do serviço é livre de taxas e impostos financeiros. A seguir encontra-se a metodologia utilizada neste trabalho, bem como a descrição da empresa participante do estudo de caso e os resultados encontrados após a pesquisa.

\section{Metodologia}

Esta pesquisa é de natureza aplicável, pois visa à utilização dos resultados obtidos no setor financeiro da empresa ABC. Para Prodanov e Freitas (2013) a pesquisa aplicada gera conhecimentos para solucionar problemas específicos. Segundo Cervo, Bervian e Silva (2007) o trabalho é caracterizado também como exploratório, pois buscou obter informações sobre o assunto em estudo, e descritivo por registrar e descrever os acontecimentos observados sem intervenção.

Em relação à abordagem do problema, a metodologia usada é do tipo qualitativa e quantitativa. Raupp e Beuren (2003, p.92) descrevem que "a abordagem quantitativa caracteriza-se pelo emprego de instrumentos estatísticos, tanto na coleta quanto no tratamento dos dados". Para Richardson (1999, p.79), “a abordagem qualitativa é utilizada principalmente nas pesquisas descritivas, que buscam fazer a correlação entre as variáveis e o fenômeno motivo do estudo".

Para coleta de dados foi realizado um estudo de caso na empresa $\mathrm{ABC}$ com observação não participante, e aplicado um questionário com perguntas abertas a fornecedores com volume de faturamento anual superior, baseado no ano de 2016. De acordo com Prodanov e Freitas (2013), este tipo de questionário traz liberdade aos respondentes, pois não delimita opiniões a alternativas. Os dados coletados na abordagem qualitativa foram submetidos à análise de conteúdo, seguindo os procedimentos recomendados por Bardin (2011). Já os dados que emergiram da abordagem quantitativa foram analisados com auxílio de técnicas estatísticas, com destaque para as de natureza univariada e descritiva. No próximo capítulo é apresentada a caracterização do objeto do estudo de caso e a análise dos dados coletados no presente estudo.

\section{Análise dos resultados}

Este capítulo aborda os resultados da pesquisa, iniciando com a breve apresentação da empresa participante do estudo de caso, e analisando, na sequência, a adoção do produto Risco sacado pela $\mathrm{ABC}$, como alternativa de financiamento para seus fornecedores.
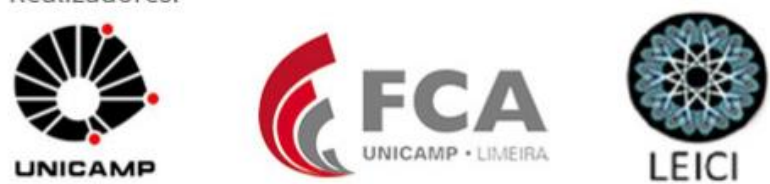


\subsection{Caracterização da empresa}

Por sua posição no mercado atualmente, a empresa ABC é considerada uma companhia líder no setor de calçados, bolsas e acessórios femininos, trabalhando com um portfólio de quatro marcas distintas. Iniciou sua história como empresa familiar na cidade de Belo Horizonte no ano de 1972, confeccionando 50 pares de sapatos masculinos por semana. Em 1974 devido à percepção da demanda, passaram a fabricar exclusivamente sapatos femininos. Em 1976, a primeira loja própria da marca foi inaugurada, desde então a ABC tornou-se uma das maiores marcas de calçados femininos da América Latina, hoje é referência em conceito, qualidade e design contemporâneo.

Por volta de 1997, a empresa transferiu sua unidade criativa, administrativa e financeira para o estado do Rio Grande do Sul, no município de Campo Bom, região do Vale dos Sinos onde encontra-se até o momento. Atualmente, a empresa conta com rede de franquias em todos os estados brasileiros, são aproximadamente 460 lojas, distribuídas em 160 municípios, além de 50 lojas próprias e um vasto canal multimarca.

O objetivo da empresa $\mathrm{ABC}$ não é apenas vender produtos, mas também proporcionar as suas clientes uma experiência de compra única a cada peça adquirida. Assim a cada coleção, a organização renova o catálogo de produtos, uniformes das vencedoras, ambientação de loja até as embalagens, buscando agregar um diferencial ao produto, valores que segundo a $\mathrm{ABC}$, não são encontrados em outras marcas.

\subsection{Análise do produto Risco Sacado na empresa ABC}

O produto Risco sacado, objeto de estudo desta pesquisa, é um programa que prevê a antecipação de recebíveis, criado pela instituição financeira Delta e implantado na empresa ABC. Essa parceria tem como finalidade facultar aos seus fornecedores a capacidade de antecipar seus recebíveis a um custo mais baixo que o de mercado, promovendo assim, mais facilidade de financiar o capital de giro das empresas, aumentando o lucro e minimizando o custo com as operações. Assaf Neto (2011) descreve o termo giro como o recurso corrente de curto prazo das empresas, o que envolve a administração dos ativos e passivos circulantes, de forma a garantir o equilíbrio das atividades operacionais financeiras.

Após uma restruturação orçamentária, a empresa ABC deixou de efetuar os pagamentos a seus fornecedores no prazo de 30 dias e passou a quitar essas dívidas em 45 dias. Todas as alterações foram efetuadas sob acordo entre empresa e fornecedor, mediante alteração contratual de prestação de serviço conforme documentos internos analisados pelo pesquisador. Por se tratar de fornecedores de pequeno e médio porte, possuem capacidade de financiamento reduzida perante a empresa $\mathrm{ABC}$. Por isto, os valores disponibilizados pelas instituições financeiras para estas organizações são pequenos, e os custos gerados na transação são altos, o que reduz o lucro e impossibilita investimentos, esta situação coloca as pequenas organizações em desvantagem perante fornecedores com maior capacidade financeira. Segundo Camargo (2014), o capital das empresas é composto de recursos próprios, ou seja, dos acionistas e de terceiros, o que incide em intuições financeiras e fornecedores. Para este autor um dos maiores desafios enfrentados pelos gestores, é a análise das fontes de

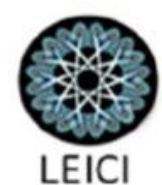


financiamento disponíveis considerando os gastos gerados pelas operações, pois minimizar os custos é essencial para obter êxito na gestão financeira.

Com intuito de não impactar o fluxo de caixa com o acréscimo de 15 dias para o recebimento, a empresa $\mathrm{ABC}$ buscou alternativas de baixo custo junto às instituições financeiras e parceiras da empresa, neste momento surgiu o produto Risco Sacado. Em primeiro momento, esta empresa idealizou um produto automatizado e sem burocracia para contratar os valores. Alguns produtos similares disponíveis no mercado foram apresentados, porém não corresponderam às expectativas da empresa. A instituição financeira Delta com interesse no montante a receber dos fabricantes, se adequou às regras impostas pela $A B C$, oferecendo-se também para custear a implantação do produto em seu sistema. Com a parceria estabelecida, iniciou-se a implantação de melhorias no sistema utilizado pela ABC, apos um ano, os primeiros testes efetivos foram realizados utilizando uma pequena amostra de fornecedores.

Em agosto do ano de 2014, foi anunciado aos fornecedores a implantação da ferramenta de antecipação de créditos pela $\mathrm{ABC}$, tornando desnecessária a contratação de outras linhas de adiantamento para suprir as obrigações diárias de cada fornecedor. $\mathrm{O}$ processo de implantação do risco sacado passou por algumas etapas, a saber: (i)parametrização do sistema-cnab 240; (ii) envio de dados dos fornecedores por parte da $\mathrm{ABC}$ para Delta realizar cadastro; (iii) cadastro prévio realizado pela Delta e envio de código de convite aos fornecedores; (iv)finalização de cadastros após confirmação de fornecedores; (v) envio de NFs disponíveis para pagamento antecipado pela ABC; (vi) notas disponibilizadas no site pela Delta; (vii) antecipação efetuada pelo fornecedor; (viii) arquivo disponibilizado pela Delta para retorno das operações efetuadas; (ix) processamento do arquivo no sistema para efetuar a baixa das notas processadas. Caso não seja efetuada, a NF é excluída automaticamente do site sete dias antes do vencimento.

Buscando demonstrar a relevância da implantação na empresa $\mathrm{ABC}$ do produto Risco Sacado, foi aplicado um questionário para fornecedores que demonstraram volume de faturamento superior no período de 10 a 19 de maio de 2016. Foram entrevistados 23 (vinte e três) fornecedores, desses 16 (dezesseis) responderam a pesquisa, o que corresponde a $70 \%$ da amostra.

Com base nas respostas obtidas através do questionário, afirma-se que o valor total de faturamento para a ABC no ano de 2015, somando os resultados de todos os fornecedores, foi de 500.895.835,06, deste valor, foi antecipado utilizando o Risco Sacado, à quantia de $346.130 .832,06$, ou seja, cerca de 52\% dos fornecedores anteciparam mais de $90 \%$ do seu faturamento. Tal informação reforça o pensamento de Viana (2013), o qual destaca que, independentemente do porte, todas as empresas necessitam de capital de giro para atender as suas necessidades financeiras e dar continuidade em suas atividades. Assaf Neto (2011) complementa a ideia afirmando que o ciclo operacional de cada empresa pode ser definido por etapas, cada uma delas é representada por um determinado período, cujo a soma demonstra o tempo médio entre a compra da matéria-prima para o início da produção e o recebimento dos valores das vendas. Sendo assim é possível afirmar que quanto mais longo for o período das etapas do ciclo operacional, maior será a necessidade de recursos financeiros para financiar o capital de giro da empresa.
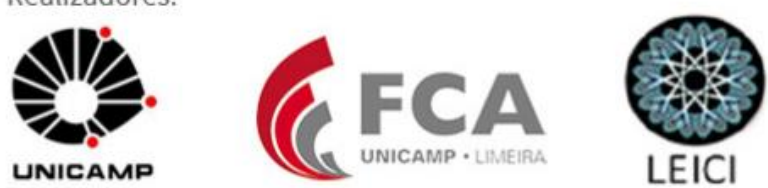
Apenas $22 \%$ dos fornecedores utilizaram menos de $50 \%$ do seu faturamento com o produto Risco Sacado. Tal fato demonstra que essas empresas possuem maior capacidade de recursos financeiros internos, e não necessitam de aumentos consideráveis de capital de giro para se manter. Dos respondentes, apenas um fornecedor não antecipa valor algum do seu contas a receber utilizando o produto em questão, ou outra instituição financeira de acordo com dados internos obtidos na empresa ABC.

O tempo de atuação no mercado varia entre os respondentes, assim como o número de colaboradores destas empresas, o segmento se restringe a calçados femininos. Os fornecedores que mais utilizam o produto Risco Sacado para a antecipação de recebíveis estão no mercado a menos de dez anos, a $\mathrm{ABC}$ não fornece matéria prima para a produção dos calçados e acessórios, cada fornecedor é responsável por custear esses insumos, o que requer um capital de giro saudável e estruturado, quando isso não é possível, a procura por crédito é necessário. A busca por crédito em bancos, instituições financeiras e cooperativas, conforme citado pela ANFAC (2015), cresceu consideravelmente no primeiro semestre de 2015 em comparação com o mesmo período do ano de 2014. Foram 5,1\% no acumulado, isto demonstra diminuição na autossuficiência de pessoas e empresas em manter-se apenas utilizando recursos próprios.

A empresa ABC possui vínculo comercial limitado por pedidos ou contrato consolidado com organizações parceiras. Conforme Pires (2014), há diferentes tipos de parcerias no que diz respeito ao relacionamento entre empresas e no que tange à questão referente aos contratos de prestação de serviço. Quanto ao abastecimento, os fornecedores respondentes da pesquisa afirmaram que faturam produtos para a $\mathrm{ABC}$ diariamente e o prazo para o recebimento é de quarenta e cinco dias após a data de emissão da nota fiscal. Em algumas situações, as atividades de produção, venda e cobrança não estão sincronizadas, quando isto ocorre, é necessário um controle rígido por parte da área financeira de cada uma das empresas que fatura o produto acabado.

O ciclo financeiro da empresa em estudo é representando pelo número de dias que os recursos ficam parados, entre a saída de caixa proveniente de pagamentos realizados na compra de matéria prima para confecção do produto, até o momento do recebimento dessas vendas. Gitman (2004) reforça que quanto mais exata for a estimativa de entrada em caixa, menor será a necessidade de captação de capital de giro para a organização. Apesar de o retorno ser duvidoso, ao identificar os erros operacionais que causam prejuízos, diminuem as receitas, afetam as atividades operacionais e o poder de liquidez da empresa, os riscos são amenizados. SILVA (2011)

$\mathrm{Na}$ questão referente ao aporte para as operações, percebe-se que as empresas já utilizaram diversos tipos de financiamentos para suprir necessidades de capital de giro. Atualmente estas organizações operam apenas com Risco Sacado quando se trata de financiamento para negociar com a $\mathrm{ABC}$, isso devido à taxa atrativa em relação a outros produtos oferecidos por instituições financeiras e bancos. Os fornecedores informaram que o custo médio da operação com o produto Risco Sacado está entre 1,25\% e 1,28\% a.m., enquanto outros produtos similares oscilam entre $2,00 \%$ a $4,75 \%$ a.m, os resultados demonstram diferença considerável entre os valores, e atesta que o produto disponibilizado pela empresa $\mathrm{ABC}$, tem custo menor para seus clientes perante outras linhas oferecidas no mercado financeiro.

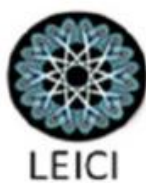


Os entrevistados afirmaram também, que não encontram empecilhos para utilizar os benefícios do produto Risco Sacado, pois a $\mathrm{ABC}$ é uma organização de grande porte e está consolidada no mercado, sendo assim, possui condições para prover os fabricantes e garantir qualidade a seus produtos. Quanto aos benefícios destacados pelos fornecedores, a agilidade e o baixo custo com a operação foram as respostas de maior destaque. Alguns fornecedores elaboraram respostas que evidenciam os benefícios do produto desenvolvido pela Delta, citam a segurança para operar, taxas competitivas e confiabilidade entre cliente e fornecedor, como principais vantagens na utilização deste produto.

\section{Conclusão}

Gerir as finanças de uma organização independentemente de seu porte, é uma tarefa complexa. Além de considerar fatores como os custos gerados, o lucro desejado, excesso de estoques, entre outros, a delimitação de recursos destinados ao capital de giro é de extrema importância, pois é este que financia o ciclo operacional e possibilita que a organizações de sequência a suas atividades.

Quando ocorre redução das vendas, gerenciamento financeiro incorreto ou algum outro imprevisto que resulta em prejuízo, empresas começam a operar com capital de giro escasso, e necessitam adquirir créditos para financiar suas atividades. Atualmente há uma grande quantidade de financiamentos disponíveis, cada um com suas particularidades, riscos e benefícios. Cabe aos responsáveis pela setor financeiro da organização, estudar e avaliar os benefícios e malefícios de cada recurso, e contratar o que melhor se adequa a realidade de sua empresa. Sendo assim, este artigo buscou analisar viabilidade do produto Risco Sacado, como alternativa de financiamento disponibilizado pela empresa ABC a seus fornecedores. Para alcançar o objetivo, foi realizado um estudo de caso na empresa citada, e aplicado um questionário a alguns fornecedores previamente selecionados.

É possível observar que o programa de antecipação de recebíveis desenvolvido pela instituição financeira Delta a pedido da empresa $\mathrm{ABC}$, é um processo rápido, de fácil acesso e contratação, confiável, flexível quanto a limites ou vinculo contratual, cuja aquisição é livre de taxas e impostos financeiros, e baixo custos.

Ao analisar as entrevistas feitas com alguns fornecedores da empresa ABC, percebe-se que cerca de $52 \%$ dos fornecedores anteciparam mais de $90 \%$ do seu faturamento. Apenas $22 \%$ dos fornecedores utilizaram menos de $50 \%$ do seu faturamento com o produto Risco Sacado. Dos respondentes, grande parte já utilizou diversos tipos de financiamentos para suprir as necessidades de capital de giro, mas atualmente estas organizações operam apenas com Risco Sacado, quando se trata de financiamento para negociar com a ABC.

Segundo os fornecedores, a procura pelo financiamento Risco sacado se dá devido à taxa atrativa e custos reduzidos perante outras linhas oferecidas no mercado financeiro. Após breve análise, o Produto Risco sacado demonstrou ser uma ferramenta eficaz, no auxílio a gestão do capital de giro dos fornecedores da empresa ABC. 


\section{Referências}

ANFAC. Demanda do consumidor por crédito avança 8,5\% em julho. Disponível em: < htt p://www.anfac.com.br/v3/informativos-noticias.jsp?id=1335>. Acesso em: 17 ago. 2015.

ASSAF NETO, Alexandre; SILVA, César A. T. Administração do Capital de Giro. 1. ed. São Paulo, SP: Atlas, 1997.

ASSAF NETO, Alexandre. Estrutura e análise de balanços: um enfoque econômicofinanceiro. 9. ed. São Paulo, SP: Atlas, 2010. 319 p.

Administração do Capital de Giro. 3. ed. São Paulo, SP: Atlas, 2002.

ASSAF NETO, Alexandre. Administração do Capital de Giro. 3. ed. São Paulo, SP: Atlas, 2011.214 p.

ASSAF NETO, Alexandre. Mercado Financeiro. 11. ed. São Paulo, SP: Editora Atlas S.A., 2012.

BANCO CENTRAL DO BRASIL. Definição e Histórico. Disponível em: <http://www.bcb.gov.br/?COPOMHIST>. Acesso em: 5 mai. 2016.

BARDIN, Laurence. Análise de conteúdo. edição revista e ampliada. São Paulo, SP: Edições 70, 2011. $279 \mathrm{p}$

CAMARGO, Márcia A. B. de. Aplicação do modelo fleuriet para empresas da construção civil. Trabalho de Conclusão de Curso. Universidade Feevale, 2014.

CAVALCANTE, Francisco; MISUMI, Jorge Yoshio; RUDGE, Luiz Fernando. Mercado de capitais / Comissão Nacional de Bolsas. Rio de Janeiro, RJ: Elsevier Editora Ltda., $2005-7^{\circ}$ reimpressão.

CERVO, Amado Luiz; BERVIAN, Pedro Alcino; DA SILVA, Roberto. Metodologia Científica. 6. ed. São Paulo: Pearson Education, 2007.

FERREIRA, Marcelo Andrade. Sistema Financeiro Nacional: uma abordagem introdutória dos mecanismos das instituições financeiras. Curitiba, InterSaberes, 2014.

GITMAN, Lawrence J. Princípios de Administração Financeira. 7.ed. São Paulo: Harbra, 1997. 841 p.

2004.

Princípios da Administração Financeira. $10^{\circ}$ ed. São Paulo: Pearson Prentice Hall,

2010

Princípios da Administração Financeira. $12^{\circ}$ ed. São Paulo: Pearson Prentice Hall,

JANKOVSKI, Ricardo Moacir. Mercado de Desconto de Títulos: uma análise junto aos clientes do BB - Praça Rio Negrinho/ SC.

Lunardi, Cristiane Andréia. Taxa de Juros, uma análise de seu comportamento. 2009. 36 f. Trabalho de Conclusão de Curso (Monografia) - Curso de Especialização em Marcado de Capitais, Universidade Federal do Rio Grande do Sul, Porto Alegre, RS, 2009.

MACHADO, Rogério A. Gestão do caixa: uma visão integrada dos fluxos financeiros da empresa. 2. ed. [S.1.]: BTC, Suma Econômica. 106 p. 2010.

MOURA, Luciano R. Gestão de Relacionamento com Fornecedores: análise da eficácia de programa para desenvolvimento e qualificação de fornecedores para grandes empresas. Disponível em: <http://www.teses.usp.br/teses/disponiveis/3/3136/tde-01092009-153815/pt$>$. Acesso em 20 set. 2015.

OLIVEIRA, Elisângela Leitão de. Administração de Capital de Giro. Estudo de Caso. Empresa: Sociedade Fogás Ltda. Florianópolis, 2002. 166f. Dissertação (Mestrado em

Organizadores:
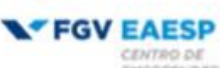

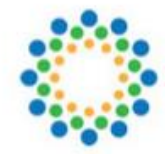

ANEGEPE

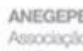

Realizadores:

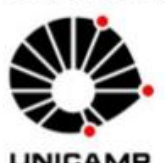

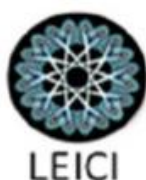


Engenharia de Produção) - Programa de Pós-graduação em Engenharia da Produção, UFSC, 2002.

PRODANOV, Cleber Cristiano; FREITAS, Ernani Cesar de. Metodologia do Trabalho Científico. 3. ed. 4 reimpr. Novo Hamburgo - RS: Feevale, 2009.

PRODANOV, Cleber Cristiano; FREITAS, Ernani Cesar de. Metodologia do Trabalho Científico. 2. ed. Novo Hamburgo - RS: Feevale, 2013.

RAUPP, Fabiano Maury; BEUREN, Ilse Maria. Metodologia da pesquisa aplicável às ciências sociais. In: BEUREN, I. M. (Org.). Como elaborar trabalhos monográficos em contabilidade: teoria e prática. São Paulo: Atlas, 2003.

RICHARDSON, Roberto Jarry. Pesquisa social: métodos e técnicas. 3 ed. São Paulo: Atlas, 1999.

VIDOR, Vanderlei. Análise de investimento em ações com a utilização de indicadores fundamentalistas. 2014. 115 f. Monografia (Conclusão do Curso de Administração) Feevale, Novo Hamburgo-RS, 2014.Disponível em <http://biblioteca.feevale.br/Monografia/MonografiaVanderleiVidor.pdf>.Acesso em : 17 abr. 2015. 